\title{
An 8-gene signature predicts the prognosis of cervical cancer following radiotherapy
}

\author{
FEI XIE ${ }^{1}$, DAN DONG $^{2}$, NA DU $^{3}$, LIANG GUO $^{4}$, WEIHUA NI $^{1}$, HONGYAN YUAN $^{1}$, \\ NANNAN ZHANG ${ }^{1}$, JIANG JIE ${ }^{1}$, GUOMU LIU $^{5}$ and GUIXIANG TAI ${ }^{1}$ \\ ${ }^{1}$ Department of Immunology, College of Basic Medical Science, Jilin University; \\ Departments of ${ }^{2}$ Obstetrics and Gynecology, ${ }^{3}$ Infections, ${ }^{4}$ Pathology and ${ }^{5}$ Nephrology, \\ The First Hospital of Jilin University, Changchun, Jilin 130021, P.R. China
}

Received July 11, 2018; Accepted May 10, 2019

DOI: $10.3892 / \mathrm{mmr} .2019 .10535$

\begin{abstract}
Gene expression and DNA methylation levels affect the outcomes of patients with cancer. The present study aimed to establish a multigene risk model for predicting the outcomes of patients with cervical cancer (CerC) treated with or without radiotherapy. RNA sequencing training data with matched DNA methylation profiles were downloaded from The Cancer Genome Atlas database. Patients were divided into radiotherapy and non-radiotherapy groups according to the treatment strategy. Differently expressed and methylated genes between the two groups were identified, and 8 prognostic genes were identified using Cox regression analysis. The optimized risk model based on the 8-gene signature was defined using the Cox's proportional hazards model. Kaplan-Meier survival analysis indicated that patients with higher risk scores exhibited poorer survival compared with patients with lower risk scores (log-rank test, $\mathrm{P}=3.22 \times 10^{-7}$ ). Validation using the GSE44001 gene set demonstrated that patients in the high-risk group exhibited a shorter survival time comprared with the low-risk group (log-rank test, $\left.\mathrm{P}=3.01 \times 10^{-3}\right)$. The area under the receiver operating characteristic curve values for the training and validation sets were 0.951 and 0.929 , respectively. Cox regression analyses indicated that recurrence and risk status were risk factors for poor outcomes in patients with CerC treated with or without radiotherapy. The present study defined that the 8 -gene signature was an independent risk factor for the prognosis of patients with CerC. The 8-gene prognostic model had predictive power for CerC prognosis.
\end{abstract}

Correspondence to: Dr Guixiang Tai, Department of Immunology, College of Basic Medical Science, Jilin University, 126 Xinmin Street, Changchun, Jilin 130021, P.R. China

E-mail: taiguixiang@163.com

Key words: cervical cancer, radiotherapy, DNA methylation, risk model, overall survival

\section{Introduction}

Cervical cancer (CerC) is a leading cause of cancer-associated mortality in women worldwide $(1,2)$. Surgery in combination with chemotherapy and radiotherapy is the most common strategy for CerC treatment. Radiotherapy significantly improves CerC patient prognosis (3). However, the overall survival of patients with CerC diagnosed at advanced stages remains poor, with the 5-year survival rate $\leq 50 \%$, despite advanced surgical protocols and diagnostic methods (4).

The general prognosis criteria of the International Federation of Gynecology and Obstetrics (FIGO) classification do not include all prognostic factors, including histologic subtypes and lymph node metastasis, which are effective for the prediction of CerC prognosis (5). Molecular markers and clinical parameters are crucial for the prediction of clinical outcomes and deciding treatment strategies $(2,5)$. In addition, the identification of biomarkers associated with radiotherapy response is of great importance for understanding the molecular mechanisms of CerC and developing novel strategies.

Radiotherapy significantly benefits patients with CerC (3). The methylation status in the promoters of a number of genes is associated with patient outcomes after radiotherapy (6-8). For example, Dunn et al (6) demonstrated that the $\mathrm{O}^{6}$-methyxlguanine-DNA-methyltransferase (MGMT) promoter methylation level was positively associated with the progression-free survival and overall survival of patients with glioblastomas treated with temozolomide and radiotherapy (6). Huang et al (7) indicated that the combined Ras association domain family member (RASSF) 1A/RASSF2A methylation level was negatively correlated with the disease-free survival (DFS) of radiotherapy-treated squamous cell carcinoma. Widschwendter et al (9) revealed that the methylated myoblast determination protein 1 (MYOD1) in CerC was associated with poor DFS (9).

An increasing number of studies have indicated the prognostic power of gene signatures for diease prognosis, metastasis and recurrence. Okayama et al (10) identified a 4 gene signature with prediction power for stage I lung cancer prognosis (10); Cheng et al (11) described an 8-gene classifier 
with predictive power for locoregional recurrence of breast cancer in patients post-mastectomy (11). Therefore, the predictive power of multigene sigatures for disease development may be of great clinical interest. A 12-gene classifier has been used for the clinical diagnosis of low and high metastasis of in uveal melanoma $(12,13)$. In addition, the DNA methylation level is a significant factor in disease development (6-8). However, to the best of our knowledge, there have been few studies investigating gene methylation signatures for prognosis in radiotherapy-treated patients with CerC.

The present study was designed to explore a novel risk model for predicting outcome of patients with CerC by analyzing RNA sequencing (RNA-seq) data in combination with matched DNA methylation profiles from The Cancer Genome Atlas (TCGA) database. A multigene risk model that predicted the outcomes of patients with CerC treated with or without radiotherapy was identified.

\section{Materials and methods}

TCGA and Gene Expression Omnibus (GEO) dataset. Training data were downloaded from TCGA database (https://gdc-portal. nci.nih.gov/) in June 2018. A total of 307 mRNA-seq profiles (Illumina Hiseq2000) and 312 DNA methylation profiles (Illumina Infinium Human Methylation 450 BeadChip) were downloaded. Paired mRNA-seq and methylation data were included in the present study. Clinical features including age, pathologic stage and grade, and survival rate of patients with CerC were extracted and used for subsequent analysis.

Validation dataset GSE44001 (GPL14951 Illumina HumanHT-12 WG-DASL V4.0 R2 expression beadchip) (14) was downloaded from the National Center of Biotechnology Information GEO database (http://www.ncbi.nlm.nih. gov/geo/). The GSE44001 dataset consists of 300 patients with primary early CerC (FIGO stage I-II). Prognostic data were available for the training and validation sets. The study design presented in Fig. 1.

Identification of differentially expressed and methylated genes. Samples from the TCGA training set were assigned into two groups according to radiotherapy treatment (with and without radiotherapy). Differentially expressed genes (DEGs) and differentially methylated genes (DMGs) between the two groups were identified using Linear Models for Microarray Data (Limma) package (version 3.34.7) in R (https://bioconductor.org/packages/release/bioc/html/limma.html). A false discovery rate $(\mathrm{FDR})<0.05$ and $\log _{2}$ fold change $(\mathrm{FC}) \mathrm{I}>0.263$ $(>1.2 \mathrm{FC})$ were set as the cutoffs. DEGs with differential methylation were selected.

Correlation analysis between gene expression and methylation level. Pearson's correlation between gene expression and the methylationlevelofDEGswascalculatedusing Cor.Testfunction (https://stat.ethz.ch/R-manual/R-devel/library/stats/html/cor.test. html) in R. DEGs with significantly correlated expression and methylation level $(\mathrm{P}<0.05)$ were included as candidate genes for subsequent analysis.

Selection of prognostic DEGs. Univariate Cox regression analysis in survival package of $\mathrm{R}$ (version 2.41.3;
https://CRAN.R-project.org/package=survival) (15) was used to screen the DEGs and DMGs associated with the prognosis of patients with CerC. $\mathrm{P}<0.05$, determined by a Kaplan-Meier log-rank test, was defined as the significant cutoff value.

Definition and validation of prognostic risk model. Cox's proportional hazards (Cox-PH) model based on the L1-penalized least absolute shrinkage and selection operator regression algorithm in the penalized package (version 0.9.50) was used for optimizing a prediction model with a linear gene signature (16). The optimized parameter 'lamba' was obtained by 1,000 rounds of cross-validated likelihood (cvl) circular calculation. The risk score of each sample was defined as the linear combination of prognostic gene expression level and Cox-PH regression coefficient: Risk score $=\sum$ coef $_{\text {gene }}$ $\mathrm{x}$ Expression (Methylation) gene. Patients were assigned into high-risk and low-risk groups according to the median value of risk score. The overall survival difference between the two groups was evaluated using Kaplan-Meier and log-rank methods in survival package of $\mathrm{R}$ (version 2.41.3; https://CRAN.R-project.org/package=survival). The GSE44001 dataset was used to validate the performance and predictive power of the prognostic risk model. The area under the time-independent receiver operating characteristic curve (AUC) was used for evaluation (2).

Selection and stratification analyses of potential clinical prognostic factors. The independent prognostic risk factors among clinical variables in TCGA patients were selected using univariate and multivariate Cox regression analysis in survival package of R (https://CRAN.R-project.org/package=survival). $\mathrm{P}<0.05$, determined by a Kaplan-Meier log-rank test, was set as the significant cutoff value. Stratification analysis was performed for patients with and without radiotherapy, with a significant threshold of $\mathrm{P}<0.05$, as determined by a log-rank test.

Bioinformatic analysis of prognostic DEGs. Patients within the training set were assigned into high-risk (samples with higher risk scores than the median) and low-risk (samples with lower risk scores than the median) groups according to the computed risk scores. DEGs between the two groups (FDR $<0.05$ and $\mid \log \mathrm{FCl}>0.263)$ were identified using Limma package in $\mathrm{R}$. Hierarchical clustering analysis of DEGs was analyzed using the Pheatmap package (version 1.0.8; https://CRAN.R-project. org/package=pheatmap) in R (17,18). Gene Set Enrichment Analysis (GSEA) $(19,20)$ was performed to identify the Kyoto Encyclopedia of Genes and Genomes (KEGG) (21) pathways significantly $(\mathrm{P}<0.05)$ associated with $\mathrm{DEG}$ between the two groups.

Statistical analysis. Continuous clinical variables, including age and overall survival, are presented as the mean \pm standard deviation (SD), and differences between groups were analyzed using Student's t-test. Differences in categorical variables, including mortality and pathological characteristics, between two groups were analyzed using Fisher's exact test. Univariate Cox regression analysis was employed for the identification of independent prognostic genes, and a two-step Cox regression analysis was used to identify independent prognostic factors 


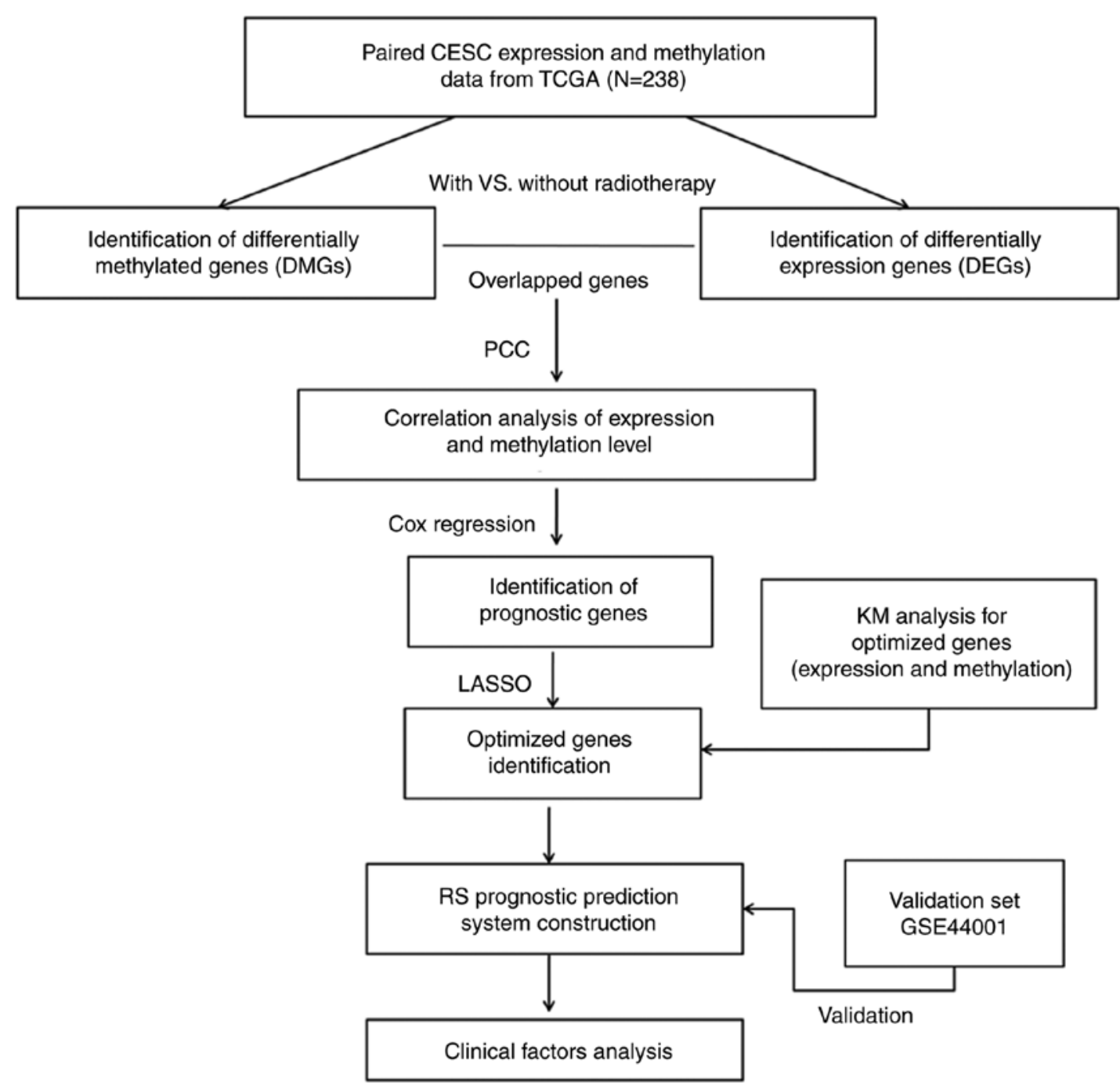

Figure 1. Flow diagram of the study design. KM, Kaplan-Meier; Lasso, least absolute shrinkage and selection operator. PCC, Pearson correlation coefficient analysis.

among clinical variables. In the stratified analysis, prognostic differences between the high-risk and low-risk patients stratification analysis were analyzed using Kaplan-Meier survival analysis. All analyses were performed in R (version 3.4.1; https://www.r-project.org/), and $\mathrm{P}<0.05$ was considered to indicate a statistically significantly difference.

\section{Results}

Baseline characteristics of patients with CerC. A total of 238 patients with CerC with paired mRNA-seq and DNA methylation profiles from TCGA were used in the present study. Table I describes the baseline characteristics of the included 238 patients. A total of 64 and 174 patients were assigned into non-radiotherapy and radiotherapy groups, respectively. Significant differences in age $\left(\mathrm{P}=3.12 \times 10^{-2}\right)$, pathologic $\mathrm{N}$ stage $\left(\mathrm{P}=2.15 \times 10^{-3}\right)$, pathologic $\mathrm{T}$ stage $\left(\mathrm{P}=1.90 \times 10^{-5}\right)$, pathologic stage $\left(\mathrm{P}=9.84 \times 10^{-5}\right)$, new tumor incidence (recurrence; $\left.\mathrm{P}=2.20 \times 10^{-16}\right)$ and therapy strategy $\left(\mathrm{P}=3.16 \times 10^{-10}\right)$ were observed between patients with and without radiotherapy. There was no difference in overall survival and survival rate between the two groups (Table I).
Identification of DEGs and DMGs in patients with CerC. There were 1,488 DEGs and 2,888 DMGs identified between the two groups (Fig. 2); the majority of the DEGs $(62.28 \%$, $1,016 / 1,488)$ were upregulated and the majority of the DMGs $(58.14 \%, 1,679 / 2,888)$ were hypomethylated by radiotherapy, compared with the non-radiotherapy group (Fig. 2A and B). There were 203 overlapping genes, with an overall negative correlation between average expression and methylation levels (Cor=-0.4045; P=2.16×10-9; Fig. 2C). Pearson's correlation analysis identified 107 genes (including 83 up- and 24 downregulated genes, Table SI) with negatively correlated expression and methylation levels.

Identification of prognostic genes. Using univariate Cox regression analysis in the survival package of $\mathrm{R}$, a total of 25 prognostic DEGs and 21 prognostic DMGs were identified from the aforementioned 107 genes (Table SII), including 8 overlapped genes, which were identified to be candidate genes associated with the prognosis of patients with CerC (Fig. 3A). The optimal 8-gene matrix was obtained using Cox-PH model ( $\max$ 'lambda'=5.8598, $\max c v l=-367.5751$; Fig. 3B). The Cox-PH regression coefficients are indicated 
Table I. Baseline characteristics of The Cancer Genome Atlas patients with cervical cancer treated with or without radiotherapy.

\begin{tabular}{|c|c|c|c|}
\hline Clinical characteristics & Without radiotherapy $(\mathrm{N}=64)$ & With radiotherapy $(\mathrm{N}=174)$ & P-value \\
\hline Age, years, mean \pm SD & $45.09 \pm 11.49$ & $49.01 \pm 14.19$ & $3.12 \times 10^{-2 a}$ \\
\hline Pathologic M (M0/M1/NA) & $29 / 1 / 34$ & $57 / 9 / 108$ & $1.65 \times 10^{-1 b}$ \\
\hline Pathologic N (N0/N1/NA) & $45 / 7 / 12$ & $58 / 35 / 81$ & $2.15 \times 10^{-3 b}$ \\
\hline Pathologic T (T1/T2/T3/T4/NA) & $47 / 9 / 0 / 4 / 4$ & $62 / 46 / 17 / 5 / 44$ & $1.902 \times 10^{-5 b}$ \\
\hline Pathologic stage (I/II/III/IV/NA) & $49 / 8 / 2 / 4 / 1$ & $78 / 47 / 29 / 16 / 4$ & $9.842 \times 10^{-5 b}$ \\
\hline Pathologic grade (1/2/3/4/NA) & $6 / 27 / 26 / 0 / 5$ & $10 / 79 / 66 / 1 / 18$ & $6.92 \times 10^{-1 b}$ \\
\hline Smoking (reformed/current/never/NA) & $7 / 12 / 38 / 7$ & $33 / 43 / 86 / 12$ & $2.06 \times 10^{-2 b}$ \\
\hline New tumor (yes/no/-) & $51 / 12 / 1$ & $31 / 142 / 1$ & $2.20 \times 10^{-16 b}$ \\
\hline Targeted molecular therapy (yes/no/NA) & $5 / 25 / 34$ & $127 / 37 / 10$ & $3.164 \times 10^{-10 b}$ \\
\hline Death (dead/alive) & $15 / 49$ & $51 / 123$ & $4.17 \times 10^{-1 b}$ \\
\hline Overall survival months, mean $\pm \mathrm{SD}$ & $35.11 \pm 43.03$ & $38.75 \pm 38.92$ & $5.54 \times 10^{-1 \mathrm{a}}$ \\
\hline
\end{tabular}

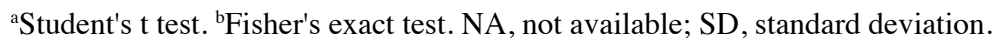

in Fig. 3C and Table II. Accordingly, 238 patients in the training set were stratified into high-expression $(n=119)$ and low-expression $(n=119)$ groups, according to the median expression value of each gene.

Subsequent Kaplan-Meier survival analyses demonstrated that the expression of coiled-coil domain containing 136 gene (CCDC136), ATP binding cassette subfamily $\mathrm{G}$ member 2 gene (ABCG2), cardiac troponin I gene (TNNI3) and Cytochrome P450 26A1 gene (CYP26Al) were positively associated with survival of patients with CerC, whereas the expression of Synaptotagmin XIII gene (SYT13), Forkhead 1 gene (FOXC2), epithelial neutrophil-activating peptide-78 gene (CXCL5) and transmembrane protein 233 gene (TMEM233) were negatively correlated (log-rank test; P<0.05; Fig. 4A; Table II). For methylation levels, analysis indicated the hypermethylation of CCDC136, ABCG2, TNNI3, and CYP26A1 genes, and the hypomethylation of $S Y T 13, F O X C 2, C X C L 5$, and TMEM233 genes was associated with the poor survival of patients with CerC $(\mathrm{P}<0.05$, log-rank test; Fig. 4B). These data demonstrated that the expression and methylation levels of these 8 genes were potential independent risk factors for prognosis in patients with CerC.

Establishment and evaluation of the risk model. The mRNA prognostic model based on the combination of Cox-PH regression coefficients and gene expression levels was established as: Risk score $=(-0.6241) \times \operatorname{Exp}_{C C D C 136}+(-1.2037) \times \operatorname{Exp}_{A B C G 2}$ $+(-1.0168) \times \operatorname{Exp}_{C Y P 26 A I}+(-1.1094) \times \operatorname{Exp}_{T N N I 3}+(0.6923) \times$ $\operatorname{Exp}_{S Y T 13}+(0.6709) \times \operatorname{Exp}_{F O X C 2}+(0.7099) \times \operatorname{Exp}_{C X C L 5}+(1.5623)$ $\mathrm{x} \operatorname{Exp}_{T M E M 233}$. According to the median risk score, 238 patients with CerC in the training set were assigned into high-risk and low-risk groups. Kaplan-Meier survival analysis indicated that patients with low-risk scores exhibited longer overall survival compared with patients with high-risk scores $\left(\mathrm{P}=3.22 \times 10^{-7}\right.$, log-rank test; Fig. 5A). The AUC was 0.951 (Fig. 5B). Analysis of the validation set GSE44001 demonstrated that patients with CerC with high-risk scores exhibited significantly shorter overall survival times compared with patients with low-risk scores $\left(\mathrm{P}=3.01 \times 10^{-3}, \log\right.$-rank test; Fig. $\left.5 \mathrm{C}\right)$, and the AUC was
0.929 (Fig. 5D). These results demonstrated that the 8-gene signature had performance and predictive power for outcomes of patients with CerC.

Prognostic value of clinical variables. A two-step Cox regression analyses (univariate and multivariate) were used to define the potential prognostic values of clinical variables, including age, pathologic stage and grade, smoking, radiotherapy, recurrence and risk status, in patients from the TCGA data. Table III demonstrates that 3 independent risk factors, including pathologic stage [hazard ratio $(\mathrm{HR})=2.386 ; 95 \%$ confidence interval (CI), 1.097-5.192; $\mathrm{P}=0.0284)$, new tumor (recurrence; $\mathrm{HR}=7.333 ; 95 \% \mathrm{CI}, 1.833-12.235 ; \mathrm{P}=3.21 \times 10^{-9}$ ) and risk status $\left(\mathrm{HR}=1.359 ; 95 \% \mathrm{CI}, 1.702-8.905 ; \mathrm{P}=1.28 \times 10^{-3}\right)$ were of prognostic value for the outcomes of patients with CerC. Kaplan-Meier survival analysis determined the prognostic potential of pathologic stage and tumor recurrence. As presented in Fig. 6, there was a significantly shorter overall survival time in patients with advanced (III-IV) pathological stages $\left(\mathrm{P}=3.21 \times 10^{-5}\right.$, log-rank test; Fig. 6A) and recurrence $\left(\mathrm{P}=9.22 \times 10^{-15}\right.$, log-rank test; Fig. 6B), compared with patients in early stage disease without recurrence.

Stratification analysis for risk factors associated with radiotherapy. To additionally confirm the risk factors associated with radiotherapy, stratified analysis for patients with radiotherapy and without radiotherapy was performed. A two-step Cox regression analyses indicated that pathologic $\mathrm{N}$ stage $\left(\mathrm{HR}=4.247 ; 95 \% \mathrm{CI}, 1.3651-6.216 ; \mathrm{P}=1.25 \times 10^{-2}\right)$, pathologic stage $\left(\mathrm{HR}=2.275 ; 95 \% \mathrm{CI}, 1.052-3.868 ; \mathrm{P}=4.53 \times 10^{-2}\right)$, recurrence $\left(\mathrm{HR}=3.841 ; 95 \% \mathrm{CI}, 1.332-5.122 ; \mathrm{P}=2.27 \times 10^{-5}\right)$ and risk status $\left(\mathrm{HR}=5.110 ; 95 \% \mathrm{CI}, 1.578-6.547 ; \mathrm{P}=6.51 \times 10^{-3}\right)$ were risk factors for radiotherapy-treated patients, whereas recurrence $\left(\mathrm{HR}=4.665 ; 95 \% \mathrm{CI}, 2.367-9.463 ; \mathrm{P}=1.58 \times 10^{-3}\right)$ and risk status $\left(\mathrm{HR}=7.546 ; 95 \% \mathrm{CI}, 1.177-8.364 ; \mathrm{P}=3.30 \times 10^{-2}\right)$ were risk factors for patients treated without radiotherapy (Table IV). These results demonstrated that recurrence and 8-gene signature risk status were independent risk factors for predicting the prognosis of patients with CerC. 
A

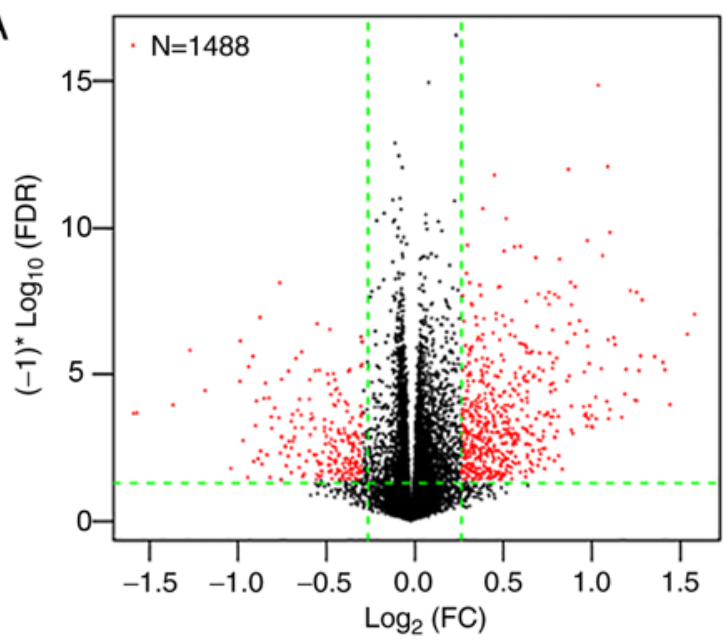

B

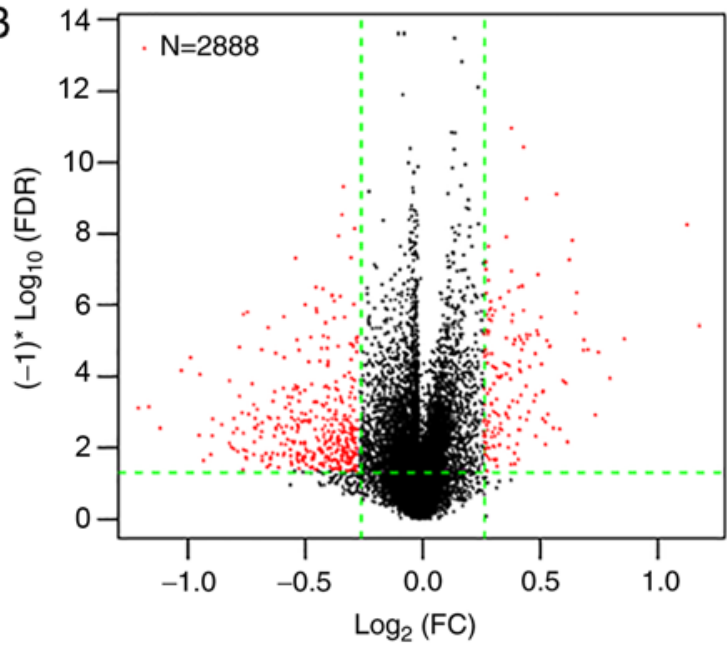

C

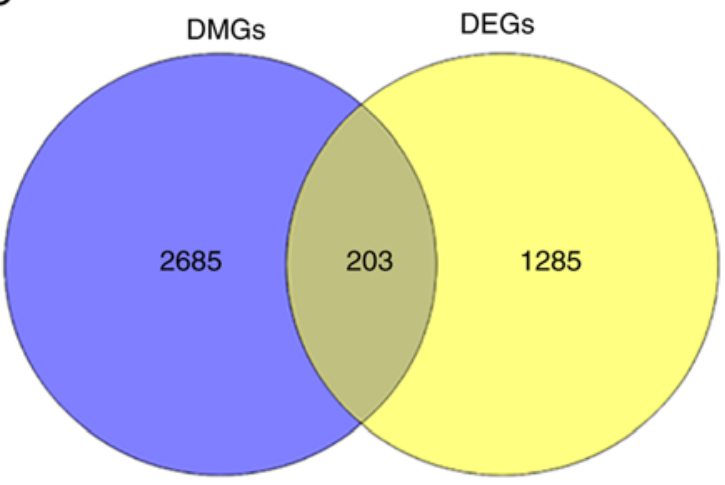

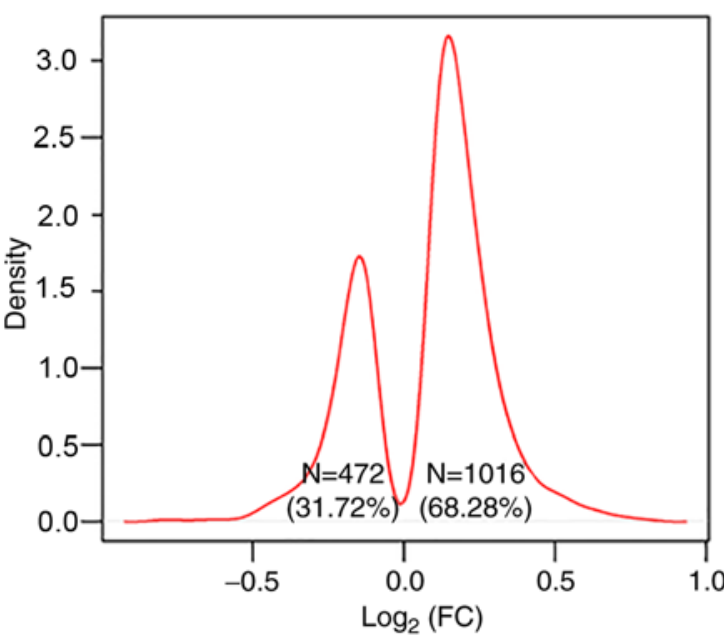
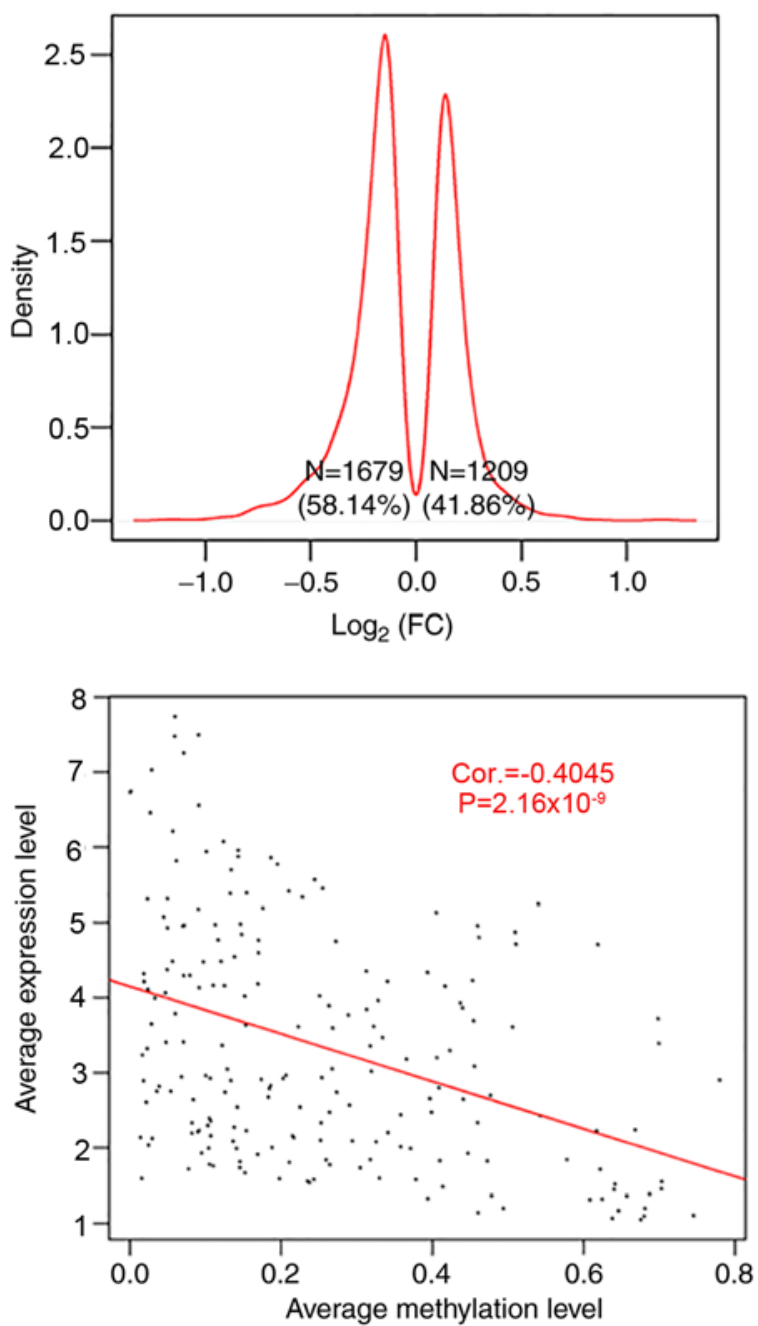

Figure 2. DEGs and DMGs between patients with and without radiotherapy. (A) Volcano plot of the DEGs (left) and the kernel density curve plot (right). (B) Volcano plot of the DMGs (left) and the kernel density curve plot (right). Green lines indicate the thresholds of FDR<0.05 (horizontal) and Ilog ${ }_{2}$ FCl $>0.263$ (vertical), respectively. (C) Identification of DEGs and DMGs levels between the two groups (right), and the Pearson's correlation analysis for average expression and methylation levels of the 203 genes. DEGs, differentially expressed genes; DMGs, differentially methylated genes; FDR, false discovery rate; FC, fold change.

Identification of DEGs and KEGG pathways associated with risk status of patients with CerC. To define the gene profiles between patients with high and low risk status, 490 DEGs were identified (Table SIII) in the high-risk group, compared with the low-risk group (Fig. 7A), including 313 upregulated DEGs $(63.88 \%$, including CXCL5, SYT13, FOXC2, ITGB3 and TMEM233) and 177 downregulated DEGs (36.18\%, including CYP26A1 and TNNI3) in the high-risk group. 
Table II. Cox's proportional hazards regression coefficients of the 8 signature genes.

\begin{tabular}{lccr}
\hline Gene & Correlation coefficient & HR (95\% CI) & P-value \\
\hline CCDC136 & -0.6241 & $0.917(0.758-0.991)$ & $2.71 \times 10^{-2}$ \\
ABCG2 & -1.2037 & $0.847(0.699-0.925)$ & $4.76 \times 10^{-2}$ \\
CYP26A1 & -1.0168 & $0.889(0.786-0.998)$ & $6.00 \times 10^{-3}$ \\
TNNI3 & -1.1094 & $0.881(0.799-0.971)$ & $4.87 \times 10^{-2}$ \\
SYT13 & 0.6923 & $1.076(1.008-1.168)$ & $4.52 \times 10^{-2}$ \\
FOXC2 & 0.6709 & $1.066(1.056-1.189)$ & $2.12 \times 10^{-3}$ \\
CXCL5 & 0.7099 & $1.075(1.006-1.160)$ & $2.48 \times 10^{-3}$ \\
TMEM233 & 1.5623 & $1.234(1.007-1.526)$ & $2.61 \times 10^{-4}$
\end{tabular}

HR, hazard ratio; CI, confidence interval; CCDC136, coiled-coil domain containing 136 gene; ABCG2, ATP binding cassette subfamily G member 2 gene; CY26A1, cytochrome P450 26A1 gene; TNNI3, cardiac troponin I gene; SYT13, synaptotagmin XIII gene; FOXC2, Forkhead 1 gene; CXCL5, epithelial neutrophil-activating peptide-78 gene; TMEM233, transmembrane protein 233 gene.
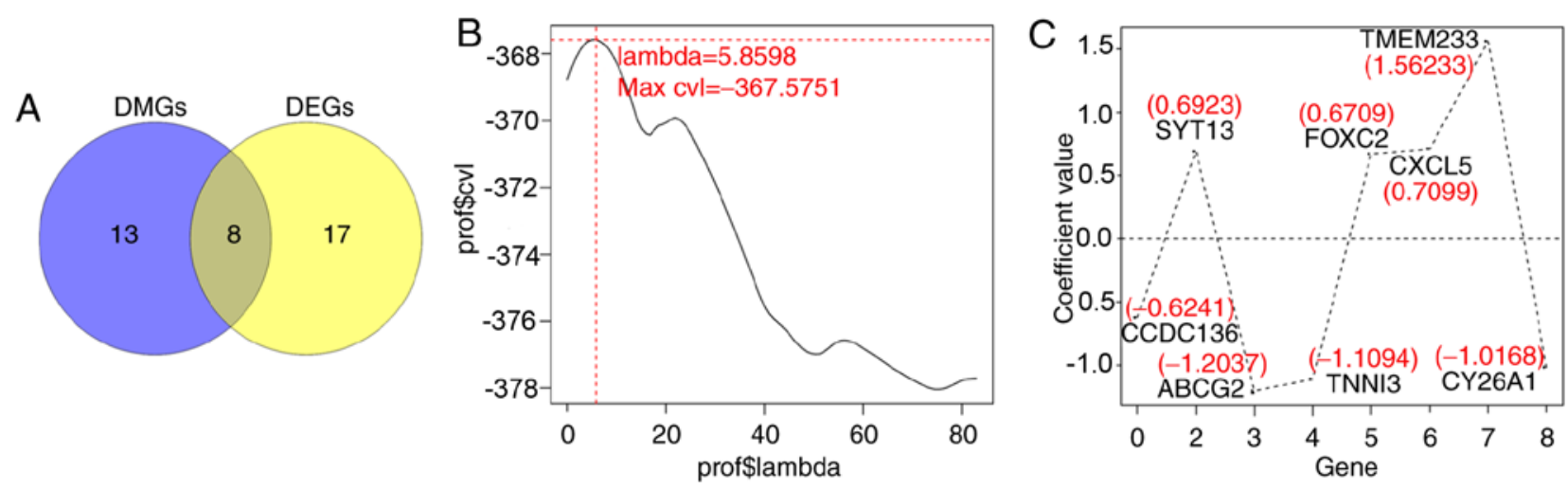

Figure 3. Selection of optimal prognostic genes using the Cox-PH model. (A) Venn diagram of overlapped DEGs and DMGs, FDR $<0.05$ and $1 \log _{2} \mathrm{FCl}$ $>0.263$. (B) The optimal 'lambda' parameters by cvl circular calculation. (C) The Cox-PH regression coefficients distribution of the 8 genes in the optimal matrix. Cox-PH, Cox's proportional hazards; DEGs, differentially expressed genes; DMGs, differentially methylated genes; cvl, Cross-validation likelihood; CCDC136, coiled-coil domain containing 136 gene; ABCG2, ATP binding cassette subfamily G member 2 gene; SYT13, synaptotagmin XIII gene; TNNI3, cardiac troponin I gene; FOXC2, Forkhead 1 gene; CXCL5, epithelial neutrophil-activating peptide-78 gene; TMEM233, transmembrane protein 233 gene; CY26A1, cytochrome P450 26A1 gene.

Fig. 7B demonstrates the markedly altered expression profiles of these DEGs in patients with low and high risk scores. GSEA KEGG pathway analysis indicated that these genes (including CYP26A1 and CXCL5) were associated with pathways including 'ECM Receptor Interaction', 'Retinol Metabolism', 'Focal Adhesion', 'Hedgehog Signaling Pathway', 'NOD-like Receptor Signaling Pathway' and 'Chemokine Signaling Pathway' (Table V).

\section{Discussion}

Identification of molecular biomarkers associated with radiotherapy may aid in devising strategies for improving radiotherapy response (22). In the present study, a large-scale analysis of RNA-seq from TCGA CerC samples, in combination with matched DNA methylation profiles, was performed, and an 8-gene risk model was identified (CCDC136, ABCG2, CYP26A1, TNNI3, CXCL5, SYT13 FOXC2, ITGB3, and TMEM233) to predict the risk status of patients with CerC. This 8-gene signature was defined to be an independent prognostic factor, with predictive power for prognosis of patients with CerC. Among these 8 genes, 4 hypermethylated genes (CCDC136, ABCG2, CYP26A1 and TNNI3) were positively associated the overall survival of patients with CerC, and 4 hypomethylated genes (SYT13, FOXC2, CXCL5 and TMEM233) were negatively associated the overall survival of patients with CerC.

The 4 hypermethylated genes (CCDC136, ABCG2, $C Y P 26 A 1$ and $T N N I 3$ ) had previously been identified to be dysregulated in various human cancer tissues (23-26). Among these, TNNI3 is an angiogenesis inhibitor responsible for the inhibition of endothelial cell tube formation $(27,28)$. Kern et al (28) suggested that metastasis was decreased in a mouse model of pancreatic cancer in response to troponin I treatment, compared with control mice. Downregulated troponin I inhibits cancer cell proliferation, as it is required for tumor growth (29). CCDC136, also known as nasopharyngeal carcinoma-associated gene 6 , is located at chromosome 7q31-32. It is commonly deleted in a number of types of malignant human cancer, and has been recognized to function as a putative tumor suppressor in gastric tumor and nasopharyngeal carcinoma $(23,30)$. 
A

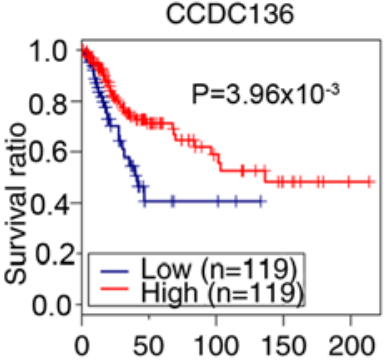

Overall survival time (months)

SYT13

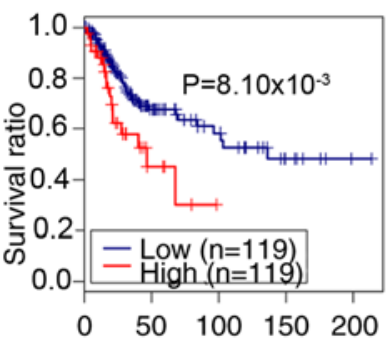

Overall survival time (months)

B cg26556186/CCDC136

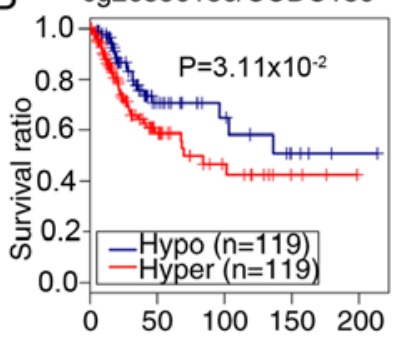

Overall survival time (months)

cg25289198/SYT13

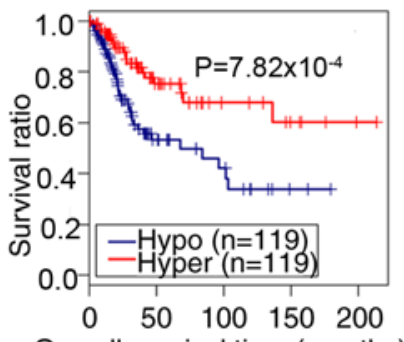

Overall survival time (months)

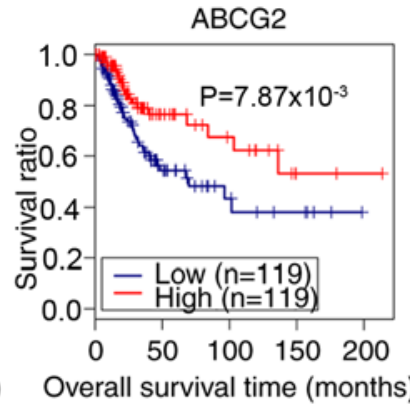

FOXC2

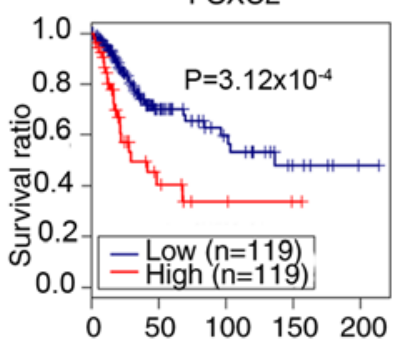

Overall survival time (months)

cg27493371/ABCG2

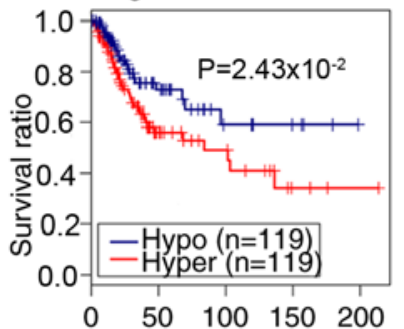

Overall survival time (months)

cg26948907/FOXC2

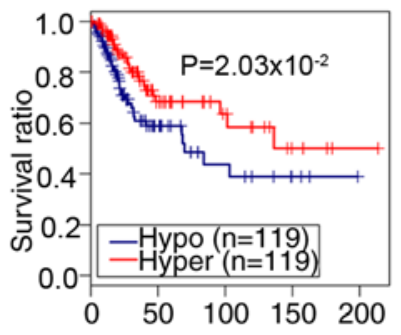

Overall survival time (months)

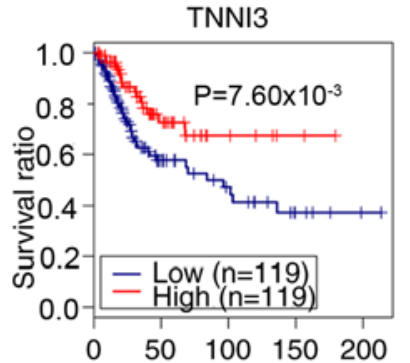

Overall survival time (months)

CXCL5

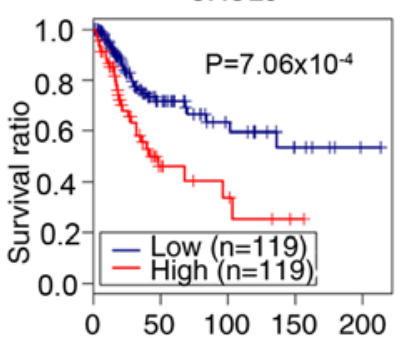

Overall survival time (months) cg22753548/TNNI3

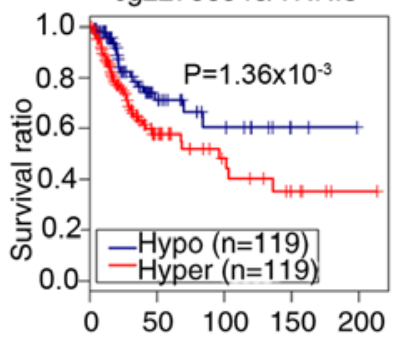

Overall survival time (months)

cg27109129/CXCL5

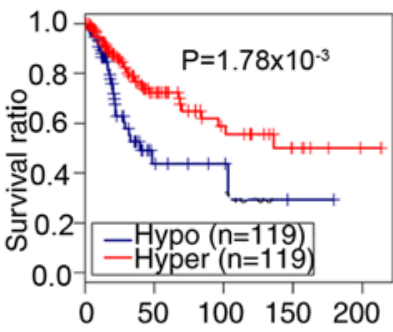

Overall survival time (months)

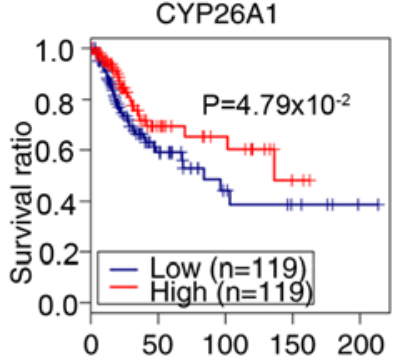

Overall survival time (months)

TMEM233

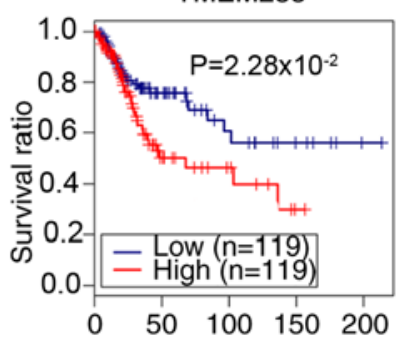

Overall survival time (months) cg26652906/CYP26A1

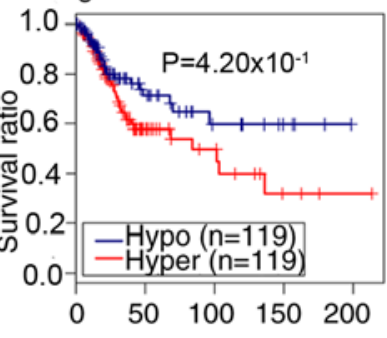

Overall survival time (months)

cg26094897/TMEM233

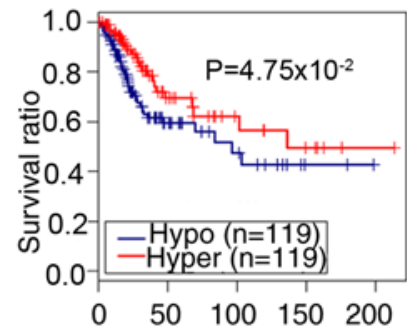

Overall survival time (months)

Figure 4. Correlation analysis of the expression and methylation levels of 8 potential prognostic genes with survival of patients with CerC. (A) Correlation between the expression of 8 genes and the prognosis of patients with CerC. Red and blue lines indicate high and low expression levels, respectively. (B) Correlation between the DNA methylation level and prognosis of patients with CerC. The number prior to the gene symbols indicates the methylation loci. Red and blue lines denote hyper- and hypomethylation, respectively. Correlation analysis was performed using Kaplan-Meier survival analysis. CCDC136, coiled-coil domain containing 136 gene; ABCG2, ATP binding cassette subfamily G member 2 gene; SYT13, synaptotagmin XIII gene; TNNI3, cardiac troponin I gene; FOXC2, Forkhead 1 gene; CXCL5, epithelial neutrophil-activating peptide-78 gene; TMEM233, transmembrane protein 233 gene; CY26A1, cytochrome P450 26A1 gene; CerC, cervical cancer.

Wei et al (30) suggested that CCDC136 negatively regulated the $W n t / \beta$-catenin signaling pathway in zebrafish embryos. $\mathrm{Wnt} / \beta$-catenin signaling is oncogenic and confers cancer cell proliferation, drug resistance and metastasis in various types of human cancer, including ovarian cancer and CerC (31-34) (Fig. 8). In the present study, it was identified that $C C D C 136$ and TNNI3 were upregulated in the radiotherapy group, compared with the non-radiotherapy group. This may be associated with the decreased angiogenesis and downregulated $\mathrm{Wnt} / \beta$-catenin signaling in patients treated with radiotherapy, which in turn is associated with the lower recurrence and improved prognosis observed in the radiotherapy group.

$A B C G 2$ encodes an multidrug transporter protein, breast cancer resistance protein (BCRP), which contributes to drug resistance in cancer cell lines and tumors $(35,36)$. It has been reported that $A B C G 2$ is downstream of $\mathrm{Wnt} / \beta$-catenin signaling and is responsible for chemoresistance (37). Downregulated $B C R P / A B C G 2$ is common in tumor tissues, including $\mathrm{CerC}$, which may function in tumorigenesis by promoting the accumulation of genotoxins and nitric oxide $(24,38,39)$. In addition, $A B C G 2$ promoter methylation has been described in multiple 
Table III. Cox regression analyses for the prognostic value of clinical variables.

\begin{tabular}{|c|c|c|c|c|}
\hline \multirow[b]{2}{*}{ Variables } & \multicolumn{2}{|c|}{ Univariate analysis } & \multicolumn{2}{|c|}{ Multivariate analysis } \\
\hline & $\mathrm{HR}(95 \% \mathrm{CI})$ & P-value & $\mathrm{HR}(95 \% \mathrm{CI})$ & P-value \\
\hline Age $(\leq 45 />45)$ & $1.014(0.996-1.032)$ & 0.138 & - & - \\
\hline Pathologic M (M0/M1) & $4.101(1.356-12.41)$ & 0.0677 & - & - \\
\hline Pathologic N (N0/N1) & $2.923(1.440-5.932)$ & $1.86 \times 10^{-3}$ & $1.535(0.711-3.315)$ & $2.76 \times 10^{-1}$ \\
\hline Pathologic T (T1/T2/T3/T4) & $1.986(1.473-2.678)$ & $2.69 \times 10^{-6}$ & $1.900(0.986-3.662)$ & $5.51 \times 10^{-2}$ \\
\hline Pathologic stage (I/II/III/IV) & $1.594(1.277-1.989)$ & $2.20 \times 10^{-5}$ & $2.386(1.097-5.192)$ & $2.84 \times 10^{-2}$ \\
\hline Pathologic grade $(1 / 2 / 3 / 4)$ & $0.943(0.612-1.452)$ & $7.89 \times 10^{-1}$ & - & - \\
\hline Smoking (reformed/current/never) & $0.984(0.719-1.346)$ & $9.18 \times 10^{-1}$ & - & - \\
\hline New tumor (yes/no) & $5.637(3.446-9.22)$ & $9.22 \times 10^{-15}$ & $7.33(1.833-12.235)$ & $3.22 \times 10^{-9}$ \\
\hline Targeted molecular therapy (yes/no) & $0.953(0.547-1.659)$ & $8.64 \times 10^{-1}$ & - & - \\
\hline Risk status (high/low) & $3.736(2.177-6.411)$ & $3.22 \times 10^{-7}$ & $1.359(1.702-8.905)$ & $1.28 \times 10^{-3}$ \\
\hline
\end{tabular}

HR, hazard ratio; CI, confidence interval.

A

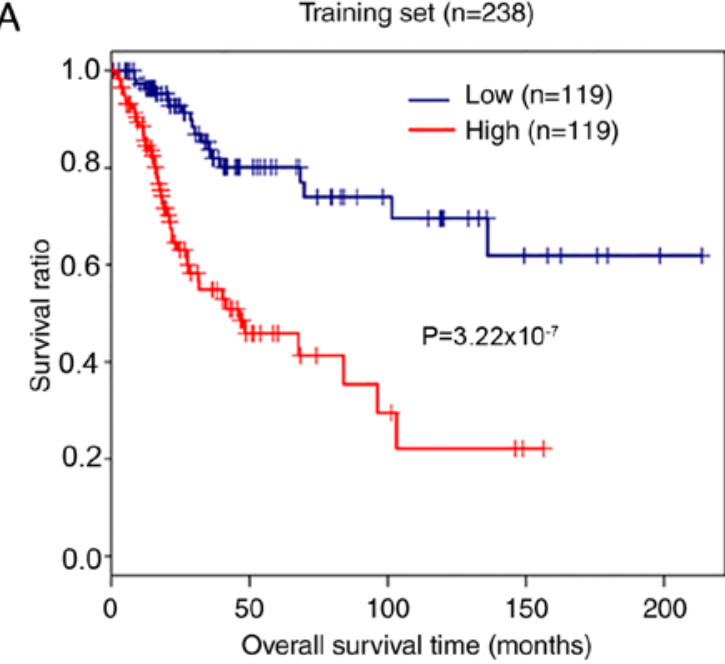

C

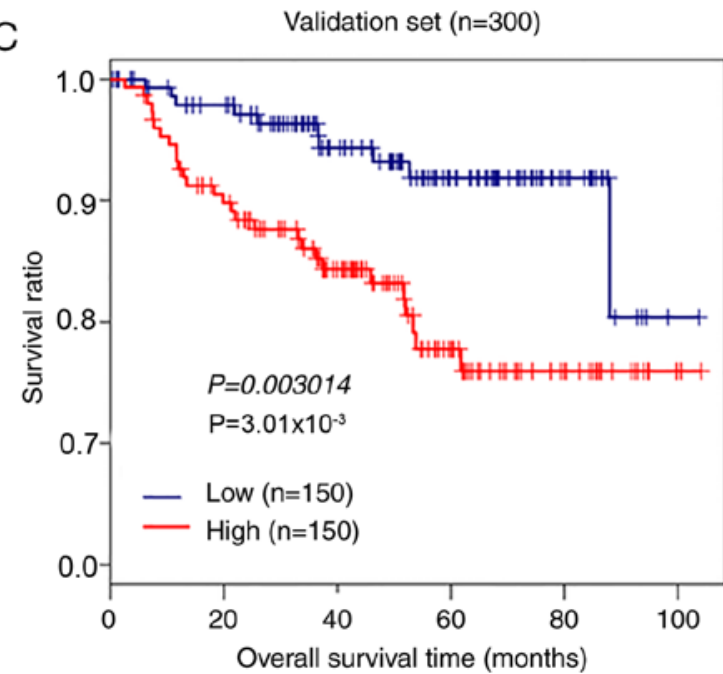

B

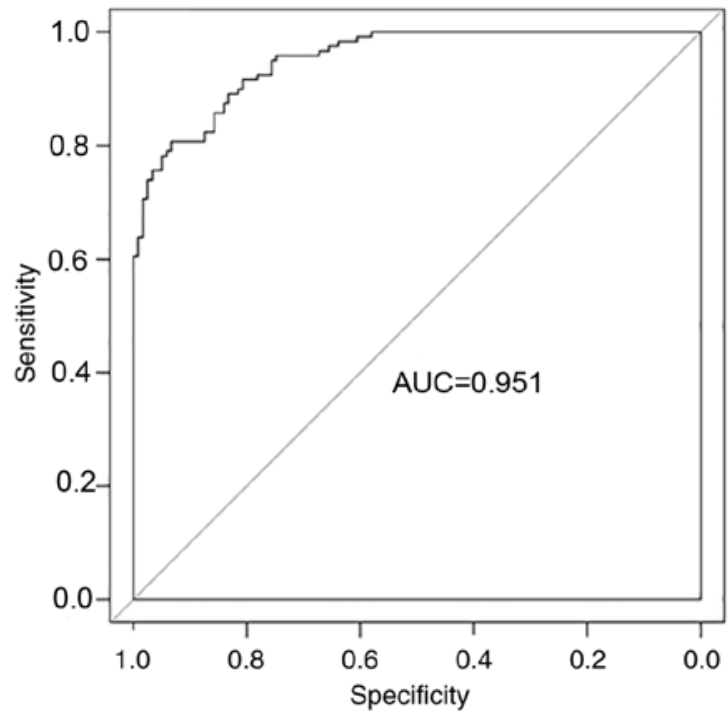

D

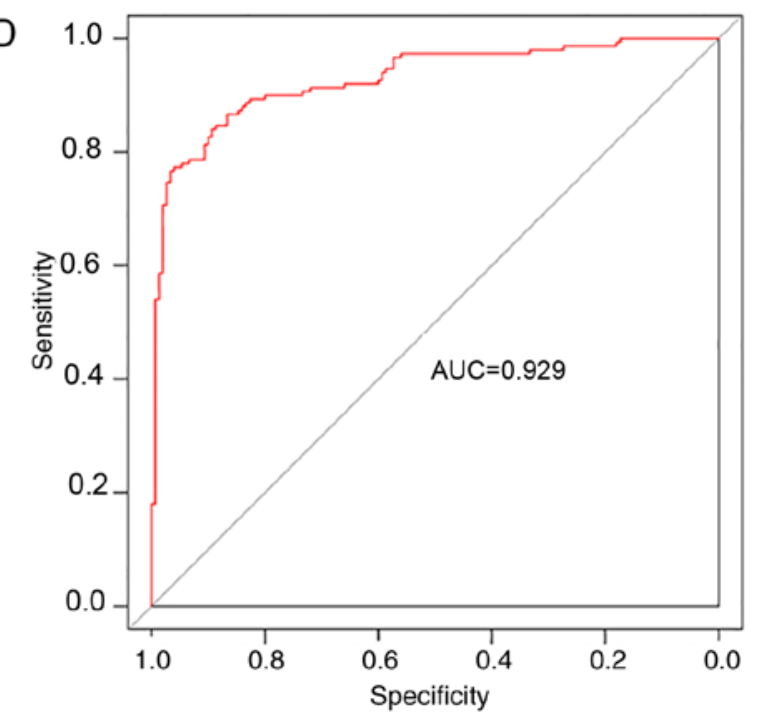

Figure 5. Kaplan-Meier survival analysis and ROC curves for the 8-gene signature in patients with cervical cancer. (A) Kaplan-Meier survival analysis and (B) ROC curve analysis for patients in TCGA training set $(\mathrm{n}=238)$. (C) Kaplan-Meier survival analysis and (D) ROC curve analysis for patients in TCGA GSE44001 validation set $(\mathrm{n}=300)$ based on the 8-gene signature risk model. ROC, receiver operating characteristic; TCGA, The Cancer Genome Atlas; AUC, area under the curve. 
Table IV. Stratification analysis for risk factors associated with radiotherapy in patients from The Cancer Genome Atlas training set.

\begin{tabular}{|c|c|c|c|c|c|c|}
\hline \multirow[b]{2}{*}{ Variables } & \multicolumn{3}{|c|}{ Univariate analysis } & \multicolumn{3}{|c|}{ Multivariate analysis } \\
\hline & HR & $95 \% \mathrm{CI}$ & P-value & HR & $95 \% \mathrm{CI}$ & P-value \\
\hline \multicolumn{7}{|l|}{ With radiotherapy $(n=174)$} \\
\hline Age $(\leq 45 />45)$ & 1.006 & $0.986-1.026$ & $5.48 \times 10^{-1}$ & - & - & - \\
\hline Pathologic M (M0/M1) & 5.457 & $1.436-10.73$ & $5.13 \times 10^{-2}$ & - & - & - \\
\hline Pathologic N (N0/N1) & 4.651 & $1.769-12.23$ & $6.31 \times 10^{-4}$ & 4.247 & $1.3651-6.216$ & $1.25 \times 10^{-2}$ \\
\hline Pathologic T (T1/T2/T3/T4) & 1.652 & $1.135-2.407$ & $7.65 \times 10^{-3}$ & 1.564 & $0.7868-3.107$ & $2.02 \times 10^{-1}$ \\
\hline Pathologic stage (I/II/III/IV) & 2.320 & $1.327-4.056$ & $2.36 \times 10^{-3}$ & 2.275 & $1.052-3.868$ & $4.53 \times 10^{-2}$ \\
\hline Pathologic grade $(1 / 2 / 3 / 4)$ & 0.878 & $0.540-1.428$ & $6.01 \times 10^{-1}$ & - & - & - \\
\hline Smoking (reformed/current/never) & 0.998 & $0.705-1.415$ & $9.95 \times 10^{-1}$ & - & - & - \\
\hline New tumor (yes/no) & 5.191 & $2.986-9.026$ & $7.89 \times 10^{-11}$ & 3.841 & $1.332-5.122$ & $2.27 \times 10^{-5}$ \\
\hline Targeted molecular therapy (yes/no) & 1.06 & $0.539-2.081$ & $.66 \times 10^{-1}$ & - & - & - \\
\hline Risk status (high/low) & 3.198 & $1.762-5.804$ & $5.51 \times 10^{-5}$ & 5.11 & $1.578-6.547$ & $6.51 \times 10^{-3}$ \\
\hline \multicolumn{7}{|l|}{ Without radiotherapy $(n=64)$} \\
\hline Age $(\leq 45 />45)$ & 1.051 & $1.004-1.1$ & $3.13 \times 10^{-2}$ & 1.031 & $0.977-1.089$ & $2.67 \times 10^{-1}$ \\
\hline Pathologic M (M0/M1) & - & - & - & - & - & - \\
\hline Pathologic N (N0/N1) & 1.348 & $0.287-2.337$ & $7.05 \times 10^{-1}$ & - & - & - \\
\hline Pathologic T (T1/T2/T3/T4) & 3.638 & $1.999-6.623$ & $2.29 \times 10^{-9}$ & 1.187 & $0.122-1.598$ & $8.83 \times 10^{-1}$ \\
\hline Pathologic stage (I/II/III/IV) & 2.462 & $1.281-3.148$ & $4.53 \times 10^{-5}$ & 2.655 & $1.243-4.007$ & $4.05 \times 10^{-1}$ \\
\hline Pathologic grade $(1 / 2 / 3 / 4)$ & 1.192 & $0.438-3.245$ & $7.31 \times 10^{-1}$ & - & - & - \\
\hline Smoking (reformed/current/never) & 0.863 & $0.395-1.882$ & $7.10 \times 10^{-1}$ & - & - & - \\
\hline New tumor $($ yes/no) & 7.802 & $2.53-14.06$ & $2.52 \times 10^{-5}$ & 4.665 & $2.367-9.463$ & $1.58 \times 10^{-3}$ \\
\hline Targeted molecular therapy (yes/no) & 1.408 & $0.998-2.181$ & $2.77 \times 10^{-1}$ & - & - & - \\
\hline Risk status (high/low) & 6.762 & $1.804-10.35$ & $1.40 \times 10^{-3}$ & 7.546 & $1.177-8.364$ & $3.30 \times 10^{-2}$ \\
\hline
\end{tabular}

HR, hazard ratio; CI, confidence interval. Risk status was predicated based on the 8-gene risk model.

A

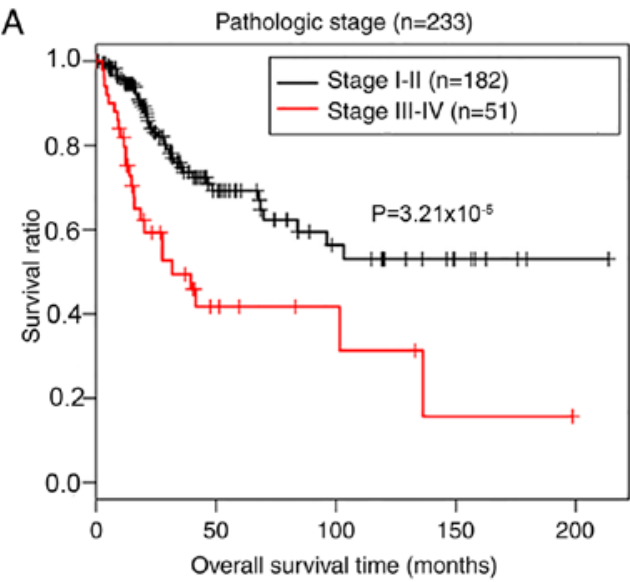

B

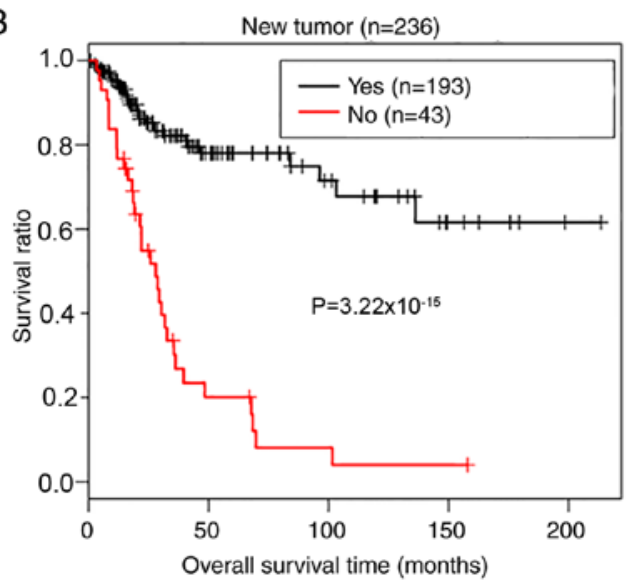

Figure 6. Kaplan-Meier survival analysis of (A) pathological stage and (B) tumor recurrence for predicting outcomes of patients in The Cancer Genome Atlas training set. Significant differences were analyzed using Kaplan-Meier log-rank test $(\mathrm{P}<0.05)$.

myeloma tissues (40). The demethylation of $A B C G 2$ increases its expression and enhances multidrug resistance in cancer cells $(40,41) . C Y P 26 A 1$ is an oncogenic protein in breast cancer, cervical squamous neoplasia, ovarian cancer, and head and neck cancer $(25,26,42)$. CYP26A1 is a metabolizing enzyme for retinoic acids (RAs) (25). RAs induce the differentiation of various types of stem cells (43), and the RA receptor $\gamma$ $(\mathrm{RAR} \gamma)$ is associated with the $\mathrm{Akt} / \mathrm{NF}-\kappa \mathrm{B}$ and $\mathrm{Wnt} / \beta$-catenin signaling pathways in tumorigenesis (44). Yasuhara et al (45) suggested that RAR $\gamma$ enhances and inhibits Wnt/ $\beta$-catenin signaling in RA-free and RA-treated conditions, respectively. Demethylation and hypermethylation of CYP26A1 had been 
Table V. Gene Set Enrichment Analysis of the KEGG pathways associated with differentially expressed genes between patients with cervical cancer with high- and low-risk scores.

\begin{tabular}{lcccl}
\hline KEGG term & ES & NES & NOM P-value & Gene \\
\hline ECM receptor interaction & 0.7695 & 1.2517 & $1.88 \times 10^{-2}$ & LAMA1, COL11A1, ITGB3, IBSP \\
Retinol Metabolism & -0.8045 & -1.2455 & $2.05 \times 10^{-2}$ & ADH7, CYP26A1, CYP26C1, UGT2A1 \\
Focal adhesion & 0.6963 & 1.2640 & $2.14 \times 10^{-2}$ & LAMA1, COL11A1, ITGB3 \\
Hedgehog signaling pathway & -0.7371 & -1.2183 & $2.34 \times 10^{-2}$ & WNT3A, BMP7 \\
NOD-like receptor signaling pathway & 0.7413 & 1.1071 & $3.98 \times 10^{-2}$ & CXCL2, IL6, IL1B \\
Chemokine signaling pathway & 0.5071 & 0.9989 & $4.72 \times 10^{-2}$ & CXCL2, CXCL6, ADCY1, CXCL3, CXCL5
\end{tabular}

KEGG, Kyoto Encyclopedia of Genes and Genomes; ECM, extracellular matrix; ES, enrichment score; NES, normalized enrichment score; NOM, nominal.
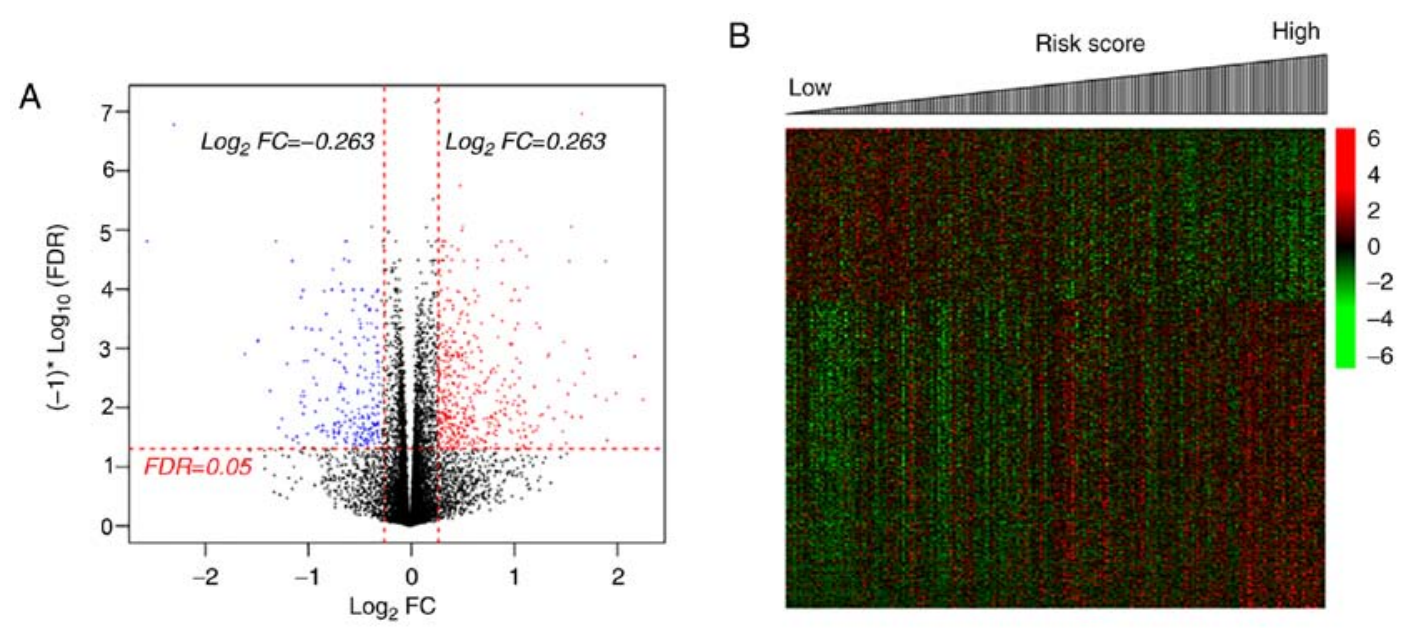

Figure 7. DEGs between patients with high- and low-risk scores. (A) Volcano plot differentially expressed genes ( $\mathrm{FDR}<0.05$ and $l \log _{2} \mathrm{FCl}>0.263$ ). (B) $\mathrm{The}$ heat map of the DEGs in The Cancer Genome Atlas patients. DEGs, differentially expressed genes; FDR, false discovery rate; FC, fold change.

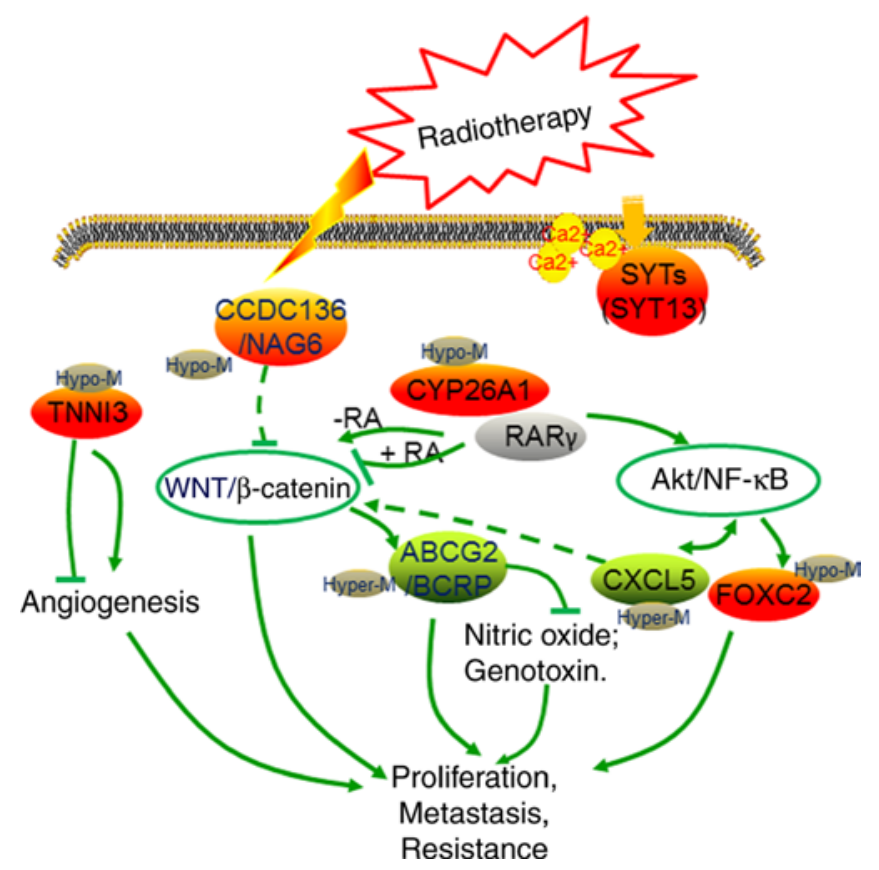

Figure 8. Graphical presentation of the radiotherapy-relevant 8-gene signature in cervical cancer. Green and red points indicate downregulated and upregulated genes in the radiotherapy group, respectively. SYT13, synaptotagmin XIII gene; CCDC136/ NAG6, coiled-coil domain containing 136 gene; TNNI3, cardiac troponin I gene; CY26A1, cytochrome P450 26A1 gene; RA, retinoic acid; RAR $\gamma$, RA receptor $\gamma$; ABCG2/BCRP, ATP binding cassette subfamily G member 2 gene; CXCL5, epithelial neutrophil-activating peptide-78 gene; FOXC2, Forkhead 1 gene. 
demonstrated in the CYP26A1-positive T47D cell line, which exhibits low rates of metastasis, and the CYP26A1-negative T47D cell line, which exhibits high rates of metastasis, respectively (46). It has been suggested that increased methylation levels in the CYP26Al promoter is associated with poor survival in patients with prostate cancer (47). In the present study, the expression levels of $A B C G 2$ and CYP26A1 were downregulated and upregulated, respectively, in patients in the radiotherapy group compared with the non-radiotherapy group. These two genes were identified to be positively associated with the prognosis of patients with CerC, and their hypermethylation was correlated with poor survival. In addition, it was also observed that $C Y P 26 A 1$ was associated with the 'Retinol Metabolism' GSEA KEGG pathway, which was associated with RA metabolism in cancer cells (48). These results suggested the complex roles of these genes in response to radiotherapy, and their potential prognostic value.

Among the 4 hypomethylated genes (SYT13, FOXC2, CXCL5 and TMEM233), SYT13, FOXC2 and CXCL5 have been demonstrated to be associated with tumorigenesis. FOXC2 is a downstream target of the $\mathrm{Akt} / \mathrm{NF}-\mathrm{kB}$ signaling pathway and is critical for tumor metastasis (49). The inhibition of FOXC2 results in the suppression of tumor metastasis and chemoresistance in lung cancer cells, nasopharyngeal carcinomas and CerC cells (49-51). Synaptotagmins are a family of $\mathrm{Ca} 2+$ sensors that function in promoting membrane fusion $(52,53)$. Overexpression of synaptotagmin has previously been described in human cancer (54-57). Kanda et al (58) demonstrated that SYT13 was upregulated in gastric cancer and was associated with metastatic status. CXCL5 is a CXC-type chemokine, and is involved in angiogenesis and associated with poor prognosis in cancer patients (59-62). In addition, $C X C L 5$ expression activated the $\mathrm{Akt} / \mathrm{NF}-\mathrm{\kappa B}$ and $\mathrm{Wnt} / \beta$-catenin signaling pathways (63-65). FOXC2 and CXCL5 were upregulated in the patients treated with radiotherapy compared with patients without radiotherapy, and their expression was associated with poor survival in patients with CerC. These demonstrated the potential prognostic value of SYT13, FOXC2 and CXCL5 for predicting patients with high risk status or poor outcomes.

In conclusion, a significant difference in survival was observed between the patients with CerC with high- and low-risk scores according to the 8 -gene signature. The AUC and survival analysis in the training and validation set revealed the performance and predictive power of the 8-gene signature risk model for predicting survival of patients with CerC. Cox regression analysis indicated that the 8-gene signature was an independent risk factor for the prognosis of patients with CerC. Validation with more and larger clinical cohorts may additionally verify the potential prognostic value of the 8-gene signature in patients with CerC.

\section{Acknowledgements}

Not applicable.

\section{Funding}

The present study was supported by grants from the Double Tenth Engineering of Major Research Project of Jilin Provincial Science and Technology Department (grant no. 20140201012YY) and the Major Development Programs for New Drugs of the Chinese Academy of Sciences during the 12th Five-Year Plan Period (grant no. 2011ZX09102-001-36).

\section{Availability of data and materials}

The results published here are in part based upon data generated by the TCGA Research Network (https://www. cancer.gov/tcga). The Gene Expression Omnibus dataset GSE44001 is available at http://www.ncbi.nlm.nih.gov/geo/. All data generated during this study are included in this published article.

\section{Authors' contributions}

FX, DD and GT were responsible for the conception and design of the research. ND, LG, WN, HY, NZ, JJ and GL acquired and analyzed the data. FX and DD drafted the manuscript. LG, WN, HY, NZ, JJ and GL revised important intellectual content. All authors agreed with the final revision.

\section{Ethics approval and consent to participate}

Not applicable.

\section{Patient consent for publication}

Not applicable.

\section{Competing interests}

The authors declare that they have no competing interests.

\section{References}

1. Cancer Genome Atlas Research Network; Albert Einstein College of Medicine; Analytical Biological Services; Barretos Cancer Hospital; Baylor College of Medicine; Beckman Research Institute of City of Hope; Buck Institute for Research on Aging; Canada's Michael Smith Genome Sciences Centre; Harvard Medical School; Helen F, et al: Integrated genomic and molecular characterization of cervical cancer. Nature 543: 378-384, 2017.

2. Huang K, Sun H, Li X, Hu T, Yang R, Wang S, Jia Y, Chen Z, Tang F, Shen J, et al: Prognostic risk model development and prospective validation among patients with cervical cancer stage IB2 to IIB submitted to neoadjuvant chemotherapy. Sci Rep 6: 27568, 2016.

3. Jadon R, Pembroke CA, Hanna CL, Palaniappan N, Evans M, Cleves AE and Staffurth J: A systematic review of organ motion and image-guided strategies in external beam radiotherapy for cervical cancer. Clin Oncol (R Coll Radiol) 26: 185-196, 2014.

4. White A, Joseph D, Rim SH, Johnson CJ, Coleman MP and Allemani C: Colon cancer survival in the United States by race and stage (2001-2009): Findings from the CONCORD-2 study. Cancer 123 (Suppl 24): S5014-S5036, 2017.

5. Obrzut B, Kusy M, Semczuk A, Obrzut M and Kluska J: Prediction of 5-year overall survival in cervical cancer patients treated with radical hysterectomy using computational intelligence methods. BMC Cancer 17: 840, 2017.

6. Dunn J, Baborie A, Alam F, Joyce K, Moxham M, Sibson R, Crooks D, Husband D, Shenoy A, Brodbelt A, et al: Extent of MGMT promoter methylation correlates with outcome in glioblastomas given temozolomide and radiotherapy. $\mathrm{Br}$ J Cancer 101: 124-131, 2009. 
7. Huang KH, Huang SF, Chen IH, Liao CT, Wang HM and Hsieh LL: Methylation of RASSF1A, RASSF2A, and HIN-1 is associated with poor outcome after radiotherapy, but not surgery, in oral squamous cell carcinoma. Clin Cancer Res 15: 4174-4180, 2009.

8. Miousse IR, Kutanzi KR and Koturbash I: Effects of ionizing radiation on DNA methylation: From experimental biology to clinical applications. Int J Radiat Biol 93: 457-469, 2017.

9. Widschwendter A, Müller HH, Fiegl H, Ivarsson L, Wiedemair A, Müller-Holzner E, Goebel G, Marth C and Widschwendter M: DNA methylation in serum and tumors of cervical cancer patients. Clin Cancer Res 10: 565-571, 2004.

10. Okayama H, Schetter AJ, Ishigame T, Robles AI, Kohno T, Yokota J, Takenoshita S and Harris CC: The expression of four genes as a prognostic classifier for stage I lung adenocarcinoma in 12 independent cohorts. Cancer Epidemiol Biomarkers Prev 23: 2884-2894, 2014.

11. Cheng SH, Horng CF, Huang TT, Huang ES, Tsou MH, Shi LS, Yu BL, Chen CM and Huang AT: An eighteen-gene classifier predicts locoregional recurrence in post-mastectomy breast cancer patients. EBioMedicine 5: 74-81, 2016.

12. Harbour JW: A prognostic test to predict the risk of metastasis in uveal melanoma based on a 15-gene expression profile. Methods Mol Biol 1102: 427-440, 2014.

13. Field MG, Decatur CL, Kurtenbach S, Gezgin G, van der Velden PA, Jager MJ, Kozak KN and Harbour JW: PRAME as an independent biomarker for metastasis in Uveal melanoma. Clin Cancer Res 22: 1234-1242, 2016

14. Lee YY, Kim TJ, Kim JY, Choi CH, Do IG, Song SY, Sohn I, Jung SH, Bae DS, Lee JW and Kim BG: Genetic profiling to predict recurrence of early cervical cancer. Gynecol Oncol 131: 650-654, 2013

15. Wang P, Wang Y, Hang B, Zou X and Mao JH: A novel gene expression-based prognostic scoring system to predict survival in gastric cancer. Oncotarget 7: 55343-55351, 2016.

16. Goeman JJ: L1 penalized estimation in the Cox proportional hazards model. Biom J 52: 70-84, 2010.

17. Wang L, Cao C, Ma Q, Zeng Q, Wang H, Cheng Z, Zhu G, Qi J, $\mathrm{Ma} \mathrm{H}$, Nian $\mathrm{H}$ and Wang Y: RNA-seq analyses of multiple meristems of soybean: Novel and alternative transcripts, evolutionary and functional implications. BMC Plant Biol 14: 169, 2014

18. Eisen MB, Spellman PT, Brown PO and Botstein D: Cluster analysis and display of genome-wide expression patterns. Proc Natl Acad Sci USA 95: 14863-14868, 1998.

19. Subramanian A, Tamayo P, Mootha VK, Mukherjee S, Ebert BL Gillette MA, Paulovich A, Pomeroy SL, Golub TR, Lander ES and Mesirov JP: Gene set enrichment analysis: A knowledge-based approach for interpreting genome-wide expression profiles. Proc Natl Acad Sci USA 102: 15545-15550, 2005.

20. Mootha VK, Lindgren CM, Eriksson KF, Subramanian A Sihag S, Lehar J, Puigserver P, Carlsson E, Ridderstråle M, Laurila E, et al: PGC-1alpha-responsive genes involved in oxidative phosphorylation are coordinately downregulated in human diabetes. Nat Genet 34: 267-273, 2003.

21. Kanehisa M, Furumichi M, Tanabe M, Sato Y and Morishima K : KEGG: New perspectives on genomes, pathways, diseases and drugs. Nucleic Acids Res 45: D353-D361, 2017.

22. Liu FF, Shi W, Done SJ, Miller N, Pintilie M, Voduc D, Nielsen TO, Nofech-Mozes S, Chang MC, Whelan TJ, et al: Identification of a Low-Risk luminal a breast cancer cohort that may not benefit from breast radiotherapy. J Clin Oncol 33: 2035-2040, 2015.

23. Zhang XM, Sheng SR, Wang XY, Bin LH, Wang JR and Li GY: Expression of tumor related gene NAG6 in gastric cancer and restriction fragment length polymorphism analysis. World J Gastroenterol 10: 1361-1364, 2004.

24. Gupta N, Martin PM, Miyauchi S, Ananth S, Herdman AV, Martindale RG, Podolsky R and Ganapathy V: Down-regulation of BCRP/ABCG2 in colorectal and cervical cancer. Biochem Biophys Res Commun 343: 571-577, 2006.

25. Osanai $M$ and Lee GH: Increased expression of the retinoic acid-metabolizing enzyme CYP26A1 during the progression of cervical squamous neoplasia and head and neck cancer. BMC Res Notes 7: 697, 2014

26. Downie D, Mcfadyen MC, Rooney PH, Cruickshank ME, Parkin DE, Miller ID, Telfer C, Melvin WT and Murray GI Profiling cytochrome P450 expression in ovarian cancer: Identification of prognostic markers. Clin Cancer Res 11: 7369-7375, 2005.
27. Wang D, Li T, Cui H and Zhang Y: Analysis of the indicating value of cardiac troponin I, tumor necrosis factor- $\alpha$, interleukin-18, Mir-1 and Mir-146b for viral myocarditis among Children. Cell Physiol Biochem 40: 1325-1333, 2016.

28. Kern BE, Balcom JH, Antoniu BA, Warshaw AL and Fernández-del Castillo C: Troponin I peptide (Glu94-Leu123), a cartilage-derived angiogenesis inhibitor: In vitro and in vivo effects on human endothelial cells and on pancreatic cancer. J Gastrointest Surg 7: 961-969, 2003.

29. Casas-Tintó S, Maraver A, Serrano M and Ferrús A: Troponin-I enhances and is required for oncogenic overgrowth. Oncotarget 7 : 52631-52642, 2016.

30. Wei S, Shang H, Cao Y and Wang Q: The coiled-coil domain containing protein $\mathrm{Ccdc} 136 \mathrm{~b}$ antagonizes maternal $\mathrm{Wnt} / \beta$-catenin activity during zebrafish dorsoventral axial patterning. J Genet Genomics 43: 431-438, 2016.

31. Kopczynski J, Kowalik A, Chłopek M, Wang ZF, Góźdź S, Lasota $\mathrm{J}$ and Miettinen $\mathrm{M}$ : Oncogenic activation of the Wnt/ $\beta$-catenin signaling pathway in signet ring stromal cell tumor of the ovary. Appl Immunohistochem Mol Morphol 24: e28-e33, 2016

32. Nagaraj AB, Joseph P, Kovalenko O, Singh S, Armstrong A, Redline R, Resnick K, Zanotti K, Waggoner S and DiFeo A: Critical role of $\mathrm{Wnt} / \beta$-catenin signaling in driving epithelial ovarian cancer platinum resistance. Oncotarget 6: 23720-23734, 2015.

33. Emons G, Spitzner M, Reineke S, Auslander N, Kramer F, Rave-Fraenk M, Gaedcke J, Ghadimi M, Ried T and Grade M: Abstract 4760: Wnt/ $\beta$-catenin signaling mediates resistance of colorectal cancer cell lines to chemoradiotherapy. Cancer Res 77: 4760-4760, 2017.

34. Lan K, Zhao Y, Fan Y, Ma B, Yang S, Liu Q, Linghu H and Wang H: Sulfiredoxin may promote cervical cancer metastasis via Wnt/ $\beta$-catenin signaling pathway. Int J Mol Sci 18: pii: E917, 2017.

35. Sarkadi B, Ozvegy-Laczka C, Német K and Váradi A: ABCG2-a transporter for all seasons. FEBS Lett 567: 116-120, 2004.

36. Elkind NB, Szentpétery Z, Apáti A, Ozvegy-Laczka C, Várady G, Ujhelly O, Szabó K, Homolya L, Váradi A, Buday L, et al: Multidrug transporter ABCG2 prevents tumor cell death induced by the epidermal growth factor receptor inhibitor Iressa (ZD1839, Gefitinib). Cancer Res 65: 1770-1777, 2005.

37. Chau WK, Ip CK, Mak AS, Lai HC and Wong AS: c-Kit mediates chemoresistance and tumor-initiating capacity of ovarian cancer cells through activation of Wnt/ $\beta$-catenin-ATP-binding cassette G2 signaling. Oncogene 32: 2767-2781, 2013.

38. Liu HG, Pan YF, You J, Wang OC, Huang KT and Zhang XH: Expression of ABCG2 and its significance in colorectal cancer. Asian Pac J Cancer Prev 11: 845-848, 2010

39. Sari FM, Yanar HT and Ozhan G: Investigation of the functional single-nucleotide polymorphisms in the BCRP transporter and susceptibility to colorectal cancer. Biomed Rep 3: 105-109, 2015.

40. Turner JG, Gump JL, Zhang C, Cook JM, Marchion D, Hazlehurst L, Munster P, Schell MJ, Dalton WS and Sullivan DM: ABCG2 expression, function, and promoter methylation in human multiple myeloma. Blood 108: 3881-3889, 2006.

41. Bram EE, Stark M, Raz S and Assaraf YG: Chemotherapeutic drug-induced ABCG2 promoter demethylation as a novel mechanism of acquired multidrug resistance 12 . Neoplasia 11: 1359-1370, 2009.

42. Chang CL, Hong E, Lao-Sirieix P and Fitzgerald RC: A novel role for the retinoic acid-catabolizing enzyme CYP26A1 in Barrett's associated adenocarcinoma. Oncogene 27: 2951-2960, 2008.

43. Tang XH and Gudas LJ: Retinoids, retinoic acid receptors, and cancer. Annu Rev Pathol 6: 345-364, 2011.

44. Huang GL, Luo Q, Rui G, Zhang W, Zhang QY, Chen QX and Shen DY: Oncogenic activity of retinoic acid receptor $\gamma$ is exhibited through activation of the Akt/NF- $\kappa \mathrm{B}$ and $\mathrm{Wnt} / \beta$-catenin pathways in cholangiocarcinoma. Mol Cell Biol 33: 3416-3425, 2013.

45. Yasuhara R, Yuasa T, Williams JA, Byers SW, Shah S, Pacifici M, Iwamoto $\mathrm{M}$ and Enomoto-Iwamoto $\mathrm{M}$ : Wnt/beta-catenin and retinoic acid receptor signaling pathways interact to regulate chondrocyte function and matrix turnover. J Biol Chem 285 317-327, 2010.

46. Francesca C, Stefano R, Gaia B, Ren M and Nicoletta S: Derangement of a factor upstream of RARalpha triggers the repression of a pleiotropic epigenetic network. PLoS One 4: e4305, 2009. 
47. Liu LY: Association of tissue promoter methylation levels of APC, RASSF1A, CYP26A1 and TBX15 with prostate cancer progression (unpublished $\mathrm{PhD}$ thesis). University of Toronto (Canada), 2012.

48. García-Mariscal A, Peyrollier K, Basse A, Pedersen E, Rühl R, van Hengel $\mathrm{J}$ and Brakebusch C: RhoA controls retinoid signaling by ROCK dependent regulation of retinol metabolism. Small GTPases 9: 433-444, 2018

49. Yu YH, Chen HA, Chen PS, Cheng YJ, Hsu WH, Chang YW, Chen YH, Jan Y, Hsiao M, Chang TY, et al: MiR-520h-mediated FOXC2 regulation is critical for inhibition of lung cancer progression by resveratrol. Oncogene 32: 431-443, 2013.

50. Zheng $\mathrm{CH}$, Quan Y, Li YY, Deng WG, Shao WJ and Fu Y: Expression of transcription factor FOXC2 in cervical cancer and effects of silencing on cervical cancer cell proliferation. Asian Pac J Cancer Prev 15: 1589-1595, 2014.

51. Zhou Z, Zhang L, Xie B, Wang X, Yang X, Ding N, Zhang J, Liu Q, Tan G, Feng D and Sun LQ: FOXC2 promotes chemoresistance in nasopharyngeal carcinomas via induction of epithelial mesenchymal transition. Cancer Lett 363: 137-145, 2015.

52. Martens S, Kozlov MM and Mcmahon HT: How synaptotagmin promotes membrane fusion. Science 316: 1205-1208, 2007.

53. Geppert M, Goda Y, Hammer RE, Li C, Rosahl TW, Stevens CF and Südhof TC: Synaptotagmin I: A major Ca2+ sensor for transmitter release at a central synapse. Cell 79: 717-727, 1994.

54. Jahn JE and Coleman WB: Phenotypic normalization of GN6TF rat liver tumor cells results from WT1 expression following transfection of human SYT13-containing BACs. FASEB J 20: A1091, 2006

55. Kanda M, Shimizu D, Tanaka H, Tanaka C, Kobayashi D, Hayashi M, Iwata N, Niwa Y, Yamada S, Fujii T, et al: Significance of SYT8 For the detection, prediction, and treatment of peritoneal metastasis from gastric cancer. Ann Surg 267: 495-503, 2016

56. Sung HY, Han J, Ju W and Ahn JH: Synaptotagmin-like protein 2 gene promotes the metastatic potential in ovarian cancer. Oncol Rep 36: 535-541, 2016.

57. Jin $\mathrm{H}, \mathrm{Xu} \mathrm{G}$, Zhang Q, Pang Q and Fang M: Synaptotagmin-7 is overexpressed in hepatocellular carcinoma and regulates hepatocellular carcinoma cell proliferation via Chk1-p53 signaling. Onco Targets Ther 10: 4283-4293, 2017.
58. Kanda M, Shimizu D, Tanaka H, Tanaka C, Kobayashi D, Hayashi M, Takami H, Niwa Y, Yamada S, Fujii T, et al: Synaptotagmin XIII expression and peritoneal metastasis in gastric cancer. Br J Surg 105: 1349-1358, 2018.

59. Li A, King J, Moro A, Sugi MD, Dawson DW, Kaplan J, Li G, Lu X, Strieter RM, Burdick M, et al: Overexpression of CXCL5 is associated with poor survival in patients with pancreatic cancer. Am J Pathol 178: 1340-1349, 2011.

60. Park JY, Park KH, Bang S, Kim MH, Lee JE, Gang J, Koh SS and Song SY: CXCL5 overexpression is associated with late stage gastric cancer. J Cancer Res Clin Oncol 133: 835-840, 2007.

61. Kawamura M, Toiyama Y, Tanaka K, Saigusa S, Okugawa Y, Hiro J, Uchida K, Mohri Y, Inoue Y and Kusunoki M: CXCL5, a promoter of cell proliferation, migration and invasion, is a novel serum prognostic marker in patients with colorectal cancer. Eur J Cancer 48: 2244-2251, 2012.

62. Begley L, Kasina S, Mehra R, Adsule S, Admon AJ, Lonigro RJ, Chinnaiyan AM and Macoska JA: CXCL5 promotes prostate cancer progression. Neoplasia 10: 244-254, 2008.

63. Wang C, Li A, Yang S, Qiao R, Zhu X and Zhang J: CXCL5 promotes mitomycin $\mathrm{C}$ resistance in non-muscle invasive bladder cancer by activating EMT and NF- $\kappa$ B pathway. Biochem Biophys Res Commun 498: 862-868, 2018.

64. Guan Z, Li C, Fan J, He D and Li L: Androgen receptor (AR) signaling promotes RCC progression via increased endothelial cell proliferation and recruitment by modulating $\mathrm{AKT} \rightarrow \mathrm{NF}-\kappa \mathrm{B} \rightarrow \mathrm{CXCL5}$ signaling. Sci Rep 6: 37085, 2016.

65. Zhao J, Ou B,Han D, Wang P,Zong Y,Zhu C,Liu D, Zheng M, Sun J, FengHandLuA:Tumor-derivedCXCL5 promoteshumancolorectal cancer metastasis through activation of the ERK/Elk-1/Snail and

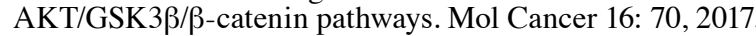

(i) $(-)$ This work is licensed under a Creative Commons Attribution-NonCommercial-NoDerivatives 4.0 International (CC BY-NC-ND 4.0) License. 